\title{
UTILIZATION OF AGRICULTURAL WASTES FOR OIL SPILLS REMEDIATION
}

\author{
Emelda A. Ongo* , Candy S. Valdecañas, and Bernard Jude M. Gutierrez
}

Industrial Technology Development Institute

\begin{abstract}
Utilization of agricultural wastes as high-value products is gaining importance not only because it reduces the volume of waste but also solves serious environmental problems. Crustacean shells and chicken eggshells are the notable wastes generated by agro-based industries. Bioconversion of these wastes for oil spill remediation is considered a very promising and challenging approach. Chitosan from shrimp shells and Calcium Carbonate $\left(\mathrm{CaCO}_{3}\right)$ from chicken eggshells are among the excellent candidates for the adsorption of oil spills due to their unique properties such as biocompatibility, biodegradability and intrinsic porous structure. In this study, different proportions of Chitosan and $\mathrm{CaCO}_{3}(50: 50 ; 40: 60$ and 30:70) were varied to determine the optimum ratio that will give the highest oil removal rate. Scanning electron microscopy (SEM) showed the detailed morphology and uniform dispersion of the needle-shaped $\mathrm{CaCO}_{3}$ on the Chitosan matrix. XRD analysis demonstrated sharp peaks at $2 \theta=9.40^{\circ}, 29.7^{\circ}, 37.3^{\circ}$ which are the characteristics of crystalline Chitosan and calcite polymorph of $\mathrm{CaCO}_{3}$. Oil removal efficiency test revealed that 50:50 Chitosan- $\mathrm{CaCO}_{3}$ composite is the optimum ratio that yield a highest oil removal efficiency of $99 \%$. The oil adsorption capacity of $50: 50$ Chitosan- $\mathrm{CaCO}_{3}$ composite is $4.03 \mathrm{~g} / \mathrm{g}$ which is 4 times of its weight.
\end{abstract}

Keywords: Chitosan, Calcium Carbonate, oil removal efficiency, adsorption capacity

\section{INTRODUCTION}

According to the Bureau of Agricultural Statistics (2011) , the Philippines produced 4.24 Million Metric Tons of chicken and duck eggs and 55,797.12 Metric Tons of Shrimp in 2010. This represents a significant amount of waste as the shells of eggs and shrimp are normally unusable and thrown away. Kitchen scraps accounts for $45 \%$ of the country's household solid waste generation, contributing to $0.50 \mathrm{~kg} /$ Capita/day of waste, or about 4,020 Metric Tons collected daily (World Bank, 2006; Bernardo, 2008). However, many useful compounds can be derived from these discarded materials, such as Chitosan from shrimp shells and Calcium Carbonate from chicken eggshells. Hence, methods that can extract these compounds from shells will be able to provide the benefits of reduced waste and added resources for industry.

Chitosan has drawn special interest as an effective biosorbent due to its low cost, biocompatibility, biodegradability, non-toxicity, and other unique properties such as film forming ability, chelation, adsorption and anti-microbial properties (Dutta et al, 2004). It is produced from the deacetylation of Chitin, a natural carbohydrate polymer found in the skeleton of crustaceans such as crab, shrimp and lobster. It is a cationic polysaccharide with a linear chain structure consisting of $\beta$-(1,4)-linked 2acetamino-2-deoxy- $\beta$-D-glucopyranose and 2amino-2-deoxy- $\beta$-D-glucopyranose. The degree of deacetylation of Chitin exceeding 50\% converts the biopolymer into Chitosan. The increase of primary amine groups in Chitosan is mainly responsible for the adsorption of cations (by chelation), anions (by electrostatic attraction) or polar molecules (by interactions as ion-dipole, dipole-dipole, Van der Waals forces, etc.) (Mendez, 2010).

Calcium Carbonate is another excellent candidate as an adsorbent material due to its intrinsic porous structure. It is naturally occurring and is the most abundant inorganic material. One of the potential

Corresponding Author: *eaongo@itdi.dost.gov.ph 
sources of Calcium Carbonate is waste chicken eggshells. Eggshells consist mainly of two materials: the calcified eggshell made of calcite and Calcium Carbonate crystals and the eggshell membrane consisting of organic matter. Dry chicken eggshells contain approximately 80-90\% Calcium Carbonate by weight (Stadelman, 2000). Several studies have also successfully applied eggshells for the treatment of environmental contaminants (Park, 2007; Witoon, 2011; Ahmed et al 2012; Tsai et al 2006).

Due to the complexity of handling oil spills and its detrimental effect to humans and the environment, it is more challenging and promising to apply these useful compounds as oil adsorbent. Oil spills impose a significant cost upon the communities affected, in the form of cleanup and social costs like loss of tourism and fishing (Cohen, 2010), not to mention the destruction of the marine ecosystem, which would have far-reaching effects over many years. While the cost estimation for the cleanup of oil spills is complex and unique to the spill in question, it has been estimated that the cleanup cost of spills for the Asia-Pacific Region, particularly in the West Philippine Sea amounts to (in 1997 US Dollars) \$16,006.22 per ton of contaminant spilled (Etkin, 1999), which is equivalent to $\$ 27,296.25 /$ ton in today's money. Therefore, there is a large imperative to find low-cost, effective solutions that could both minimize solid waste and mitigate the effects of oil spills.

\section{METHODOLOGY}

\section{Synthesis of Chitosan containing Calcium Carbonate from waste shrimp shells}

Chitosan extraction from shrimp shells usually involves the following steps: demineralization, deproteinization and deacetylation. However, in this work, the demineralization process was not performed to retain the Calcium Carbonate inherently present in shrimp shells. Deproteinization and deacetylation were carried out by alkali treatment. The resulting Calcium Carbonatecontaining Chitosan was then washed, sun-dried, ground and prepared for characterization.

\section{Extraction of Calcium Carbonate in chicken eggshells and modification to superhydrophobic and oleophilic Calcium Carbonate}

The eggshell membranes were removed and then the shells were rinsed and sun-dried. The dried eggshells were triturated and sieved with a 150mesh size. Powdered Calcium Carbonate was modified into superhydrophobic and oleophilic Calcium Carbonate in a process previously discussed by Arbatan et .al. (2011).

\section{Preparation of Chitosan- $\mathrm{CaCO}_{3}$ composite film}

Three different ratios of Chitosan and Calcium Carbonate (50:50; 40:60 and 30:70) were prepared. The Chitosan containing Calcium Carbonate from shrimp shells were dissolved in weak acid, mixed thoroughly until the solution become viscous. Then, powdered Calcium Carbonate was mixed into the solution until homogenous. The resulting mixture was poured in molding pan and dried (Figure 1).

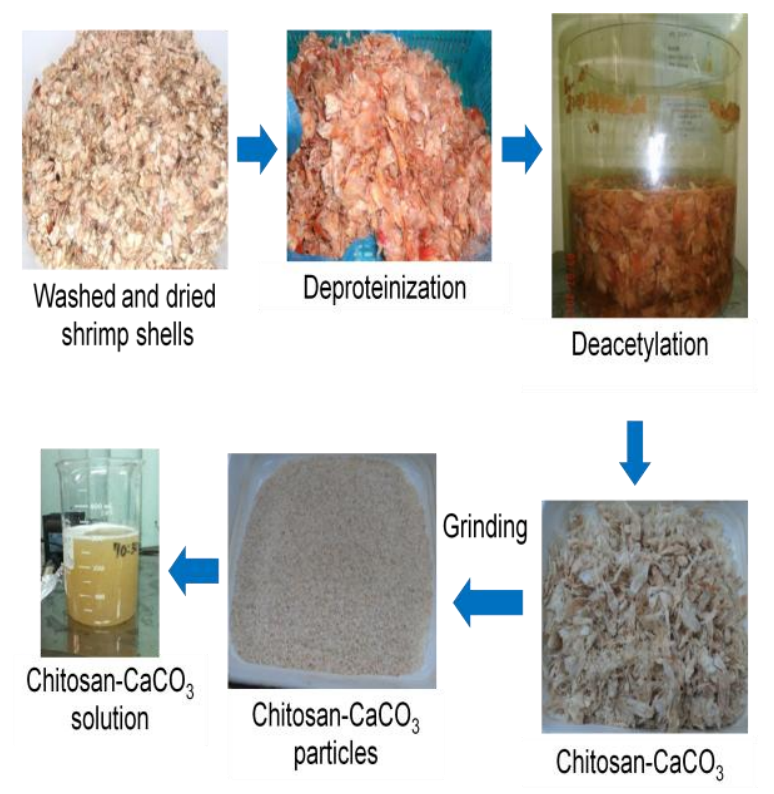

Figure 1. Process flow of Chitosan containing Calcium Carbonate extraction

\section{Analysis}

The extracted Chitosan containing $\mathrm{CaCO}_{3}$ from shrimp shells and $\mathrm{CaCO}_{3}$ from chicken eggshells were characterized using FTIR analysis. Calcium 
Carbonate content of shrimp shells and eggshells were analyzed by titrimetric method. Scanning electron microscopy (SEM; JEOL 5300, Japan) and $\mathrm{X}$-ray diffraction with $\mathrm{Cu} \mathrm{K} \alpha$ radiation (XRD; XRD-6000, Shimadzu, Japan) analyses of composite film were also performed.

\section{Treatability Study}

A preliminary treatability study of oil spills remediation using Chitosan-Calcium Carbonate composite film was carried out by preparing a simulated oil-contaminated water sample which was allowed to pass through the composite film by external pressure (Figure 2). The oil content of treated wastewater was analyzed using the standard method for oil and grease determination. The amount of oil removed after treatment was calculated and used for the determination of oil removal efficiency and oil adsorption capacity of the composite film.

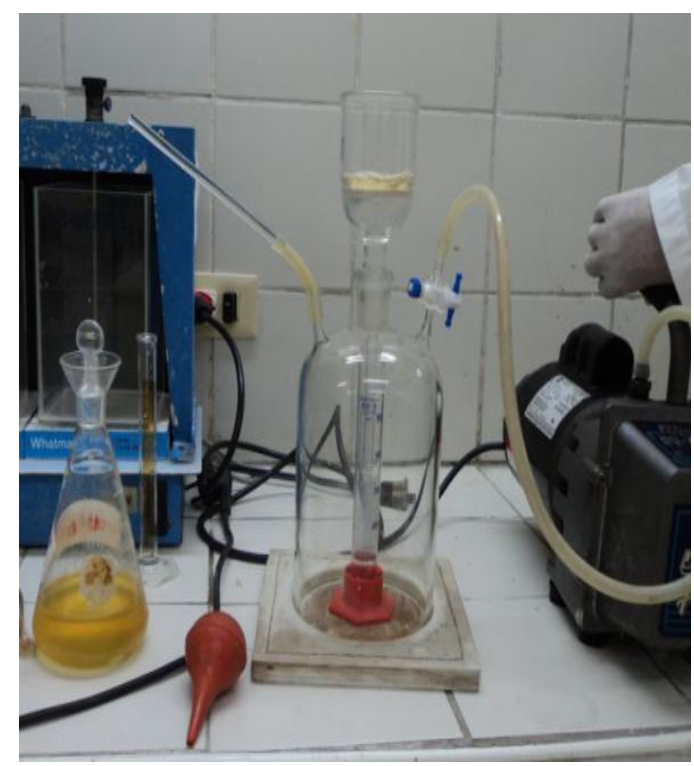

Figure 2. Treatability study set-up

\section{RESULTS AND DISCUSSION}

\section{Extraction of Chitosan containing Calcium Carbonate from waste shrimp shells}

Figures 3a-c show the FTIR spectra of Chitosan containing Calcium Carbonate from shrimp shells, standard Chitosan and standard Calcium Carbonate respectively. Chitosan containing $\mathrm{CaCO}_{3}$ spectra gave characteristics bands at $3450 \mathrm{~cm}^{-1}$ which is attributed to $\mathrm{N}-\mathrm{H}$ stretching vibration of the $\mathrm{NH}_{2}$ group and the $\mathrm{OH}$ stretching vibration. The band for amide I at $1643 \mathrm{~cm}^{-1}$ is seen in the IR spectrum of Chitosan. The characteristic carbonyl stretching of Chitosan at $1793 \mathrm{~cm}^{-1}$ is also observed. The peaks due to $\mathrm{C}-\mathrm{H}$ stretching vibrations are observed at 2923.9 and $2854.4 \mathrm{~cm}^{-1}$. The major bands that correspond to Calcium Carbonate are 1396, 872, 710. All these bands appeared to be present in the reference standard spectra of Chitosan and Calcium Carbonate which confirmed the identity of the extracted Chitosan containing Calcium Carbonate.

\section{Extraction of Calcium Carbonate from waste chicken eggshells}

The FTIR spectra of Calcium Carbonate shown in Figure 4 illustrates the most significant intensity peak of the eggshell particle at $1404 \mathrm{~cm}^{-1}$, which is strongly associated with the presence of Carbonate minerals within the eggshell matrix (Lange, 1987). There are also two observable peaks at about $709 \mathrm{~cm}^{-1}$ and $871.8 \mathrm{~cm}^{-1}$, respectively, which are associated with the in-plane deformation and outplane deformation modes, in the presence of Calcium Carbonate (Busca et al, 2000). The spectrum of Calcium Carbonate obtained from chicken eggshells is similar to the standard Calcium Carbonate which only proves that high quality Calcium Carbonate was extracted from chicken eggshells. 


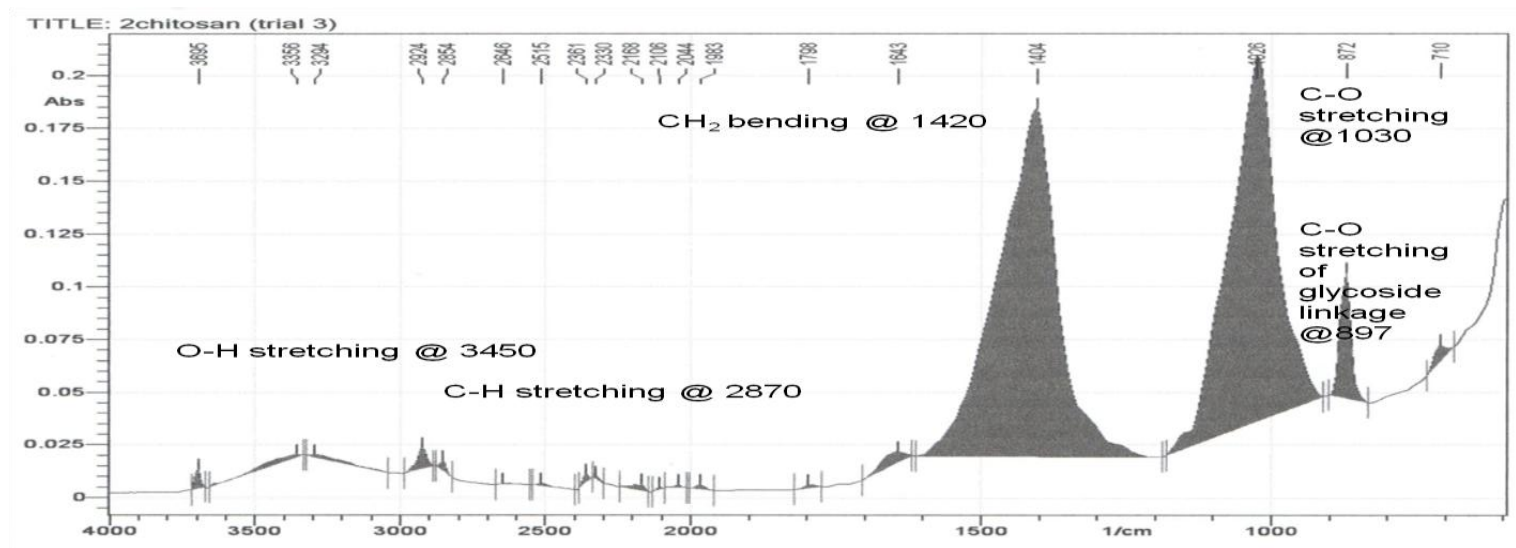

a. Extracted Chitosan containing Calcium Carbonate

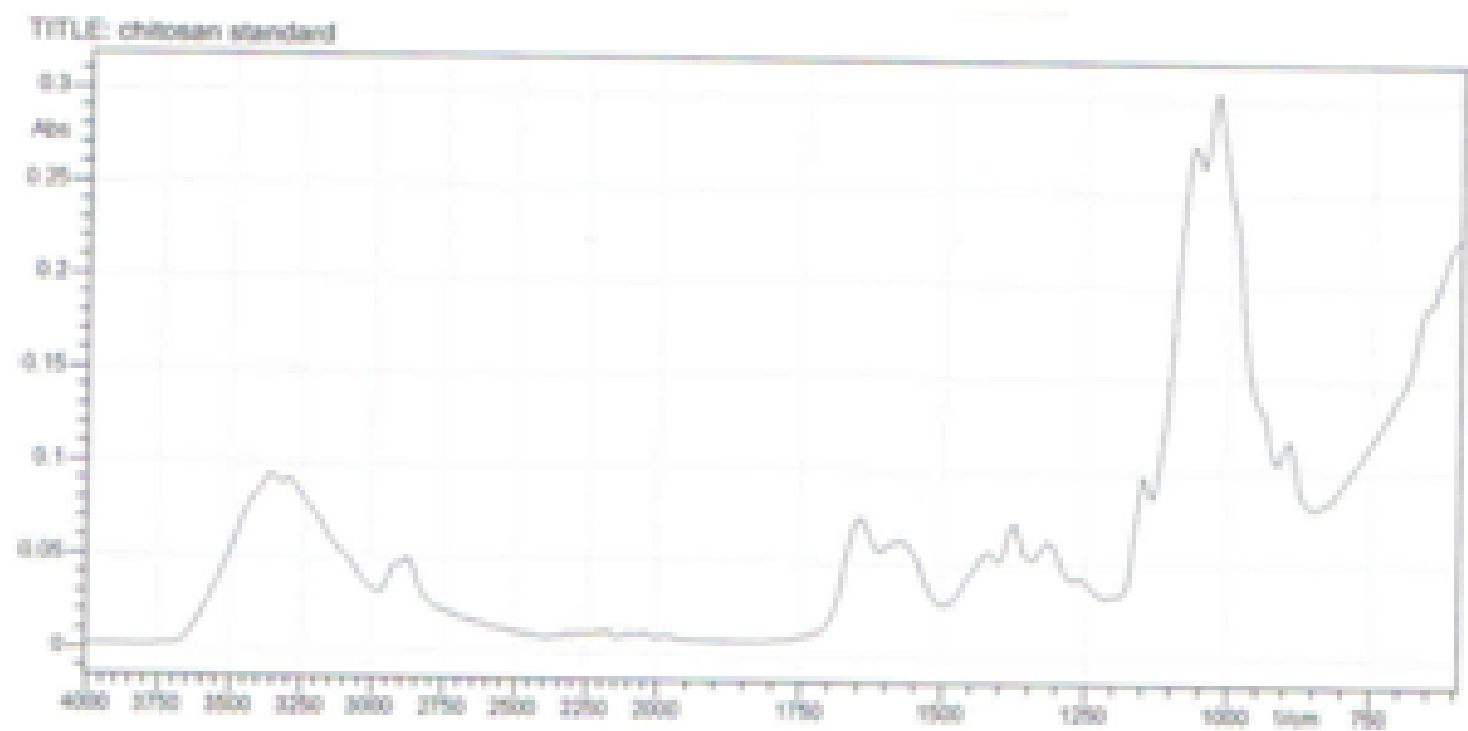

b. Standard Chitosan

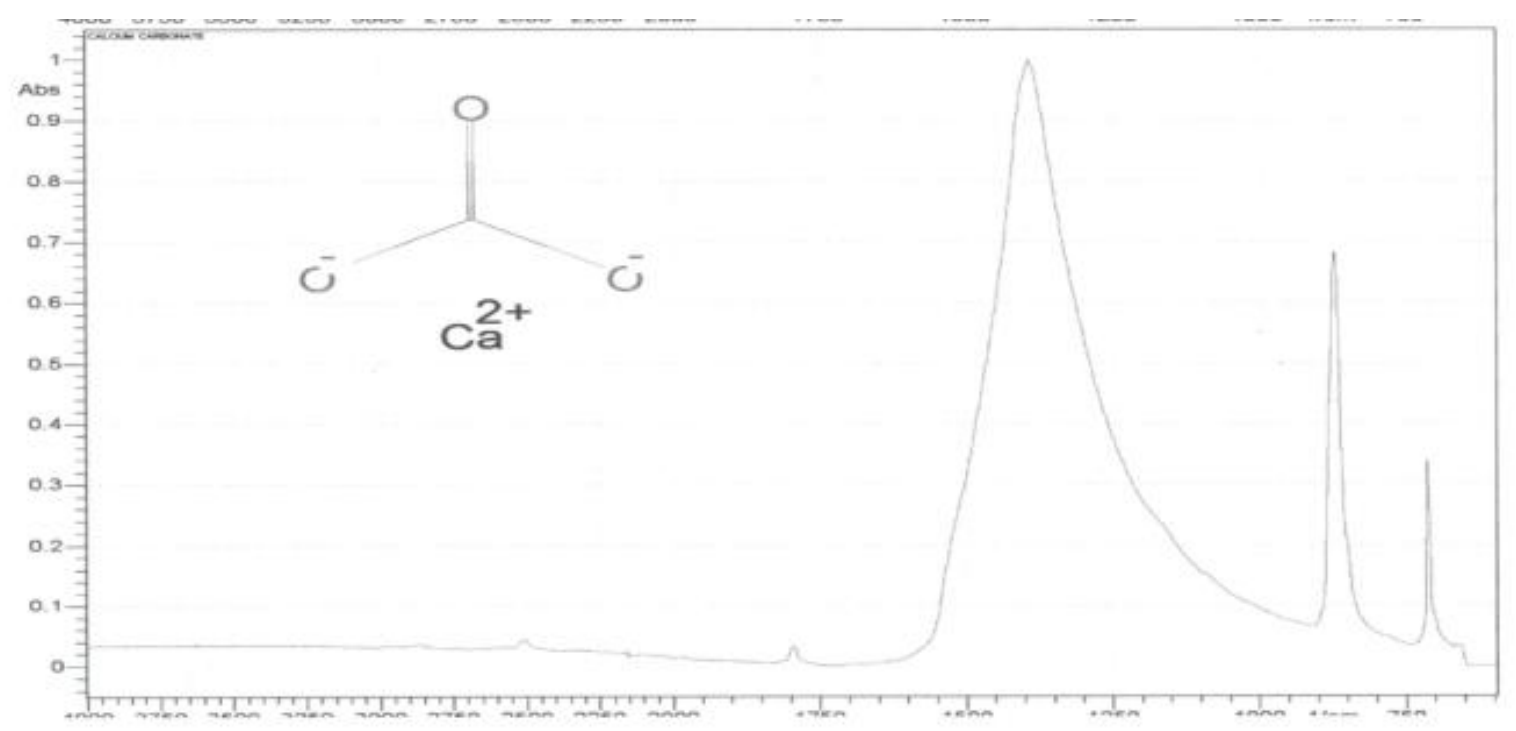

c. Standard Calcium Carbonate.

Figure 3. FTIR Spectra a) Extracted Chitosan containing Calcium Carbonate b) Standard Chitosan c) Standard Calcium Carbonate. 


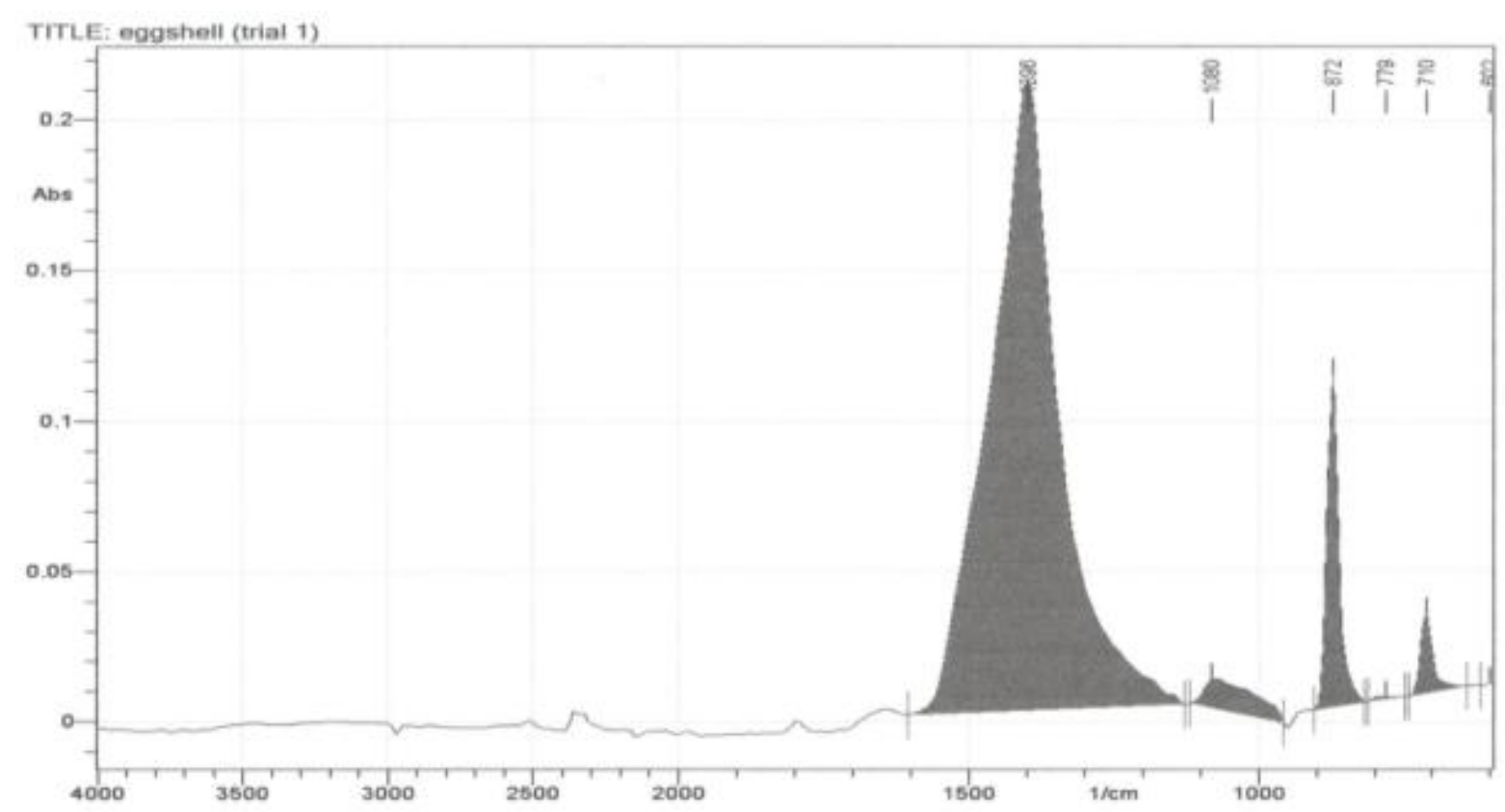

Figure 4. FTIR spectra of Calcium Carbonate from chicken eggshells.

\section{Preliminary treatment of oil contaminated wastewater using Chitosan containing $\mathrm{CaCO}_{3}$ from shrimp shells and $\mathrm{CaCO}_{3}$ from chicken eggshells}

Prior to composite film preparation, preliminary treatability of individual material was conducted to examine the potential of each material in the treatment of oil spills. Figure 5 shows the potential of the two materials in absorbing diesel oil in simulated wastewater. Chitosan containing $\mathrm{CaCO}_{3}$ extracted from shrimp shells immediately adsorbed diesel oil and formed flocs. Similarly, $\mathrm{CaCO}_{3}$ instantly absorbed the diesel oil but the agglomerated $\mathrm{CaCO}_{3}$ settled down. In the treatment of oil spills, it is more ideal and practical to obtain larger clumps that float for ease of collection and operation. Thus, $\mathrm{CaCO}_{3}$ was modified into superhydrophobic and oleophilic $\mathrm{CaCO}_{3}$.

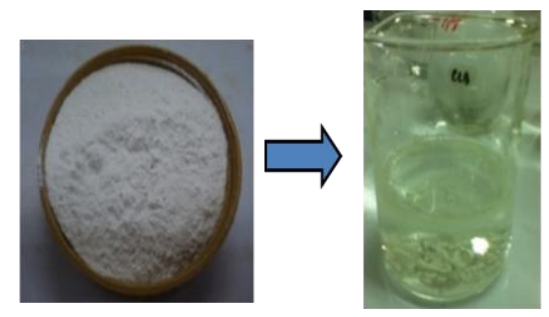

a. $\mathrm{CaCO}_{3}$ from eggshells

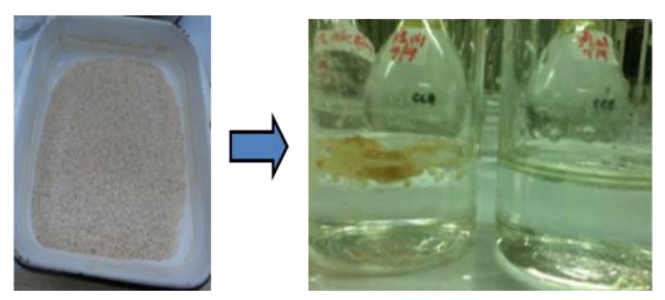

b. Chitosan containing $\mathrm{CaCO}_{3}$ from shrimp shells

Figure 5. Preliminary treatment in the removal of oil from wastewater.

\section{Determination of $\mathrm{CaCO}_{3}$ content in shrimp shells and eggshell}

Analysis showed that $\mathrm{CaCO}_{3}$ content of extracted shrimp shells is $16.7 \%$. Bellaaj et.al. (2012) reported that mineral matter in shrimp shells ranges from $15-70 \%$. The lower concentration of $\mathrm{CaCO}_{3}$ in 
shrimp shell indicates a higher amount of Chitosan in shrimp shells. It has been noted that one of the factors determining the good quality of Chitin is the low mineral content (Tolaimate et al, 2003).

Figure 6 shows the effect of acetic acid in $\mathrm{CaCO}_{3}$ content in eggshells. Acetic acid solution was used to easily remove the membrane from the shell. It was observed that raw eggshells contain $96.36 \%$ $\mathrm{CaCO}_{3}$ but after $2 \%$ acetic acid treatment, the concentration of $\mathrm{CaCO}_{3}$ reduces to $92.5 \%$ and with $4 \%$ acetic acid lowers to $92.1 \%$. Results revealed that treatment of acetic acid slightly affects the concentration of $\mathrm{CaCO}_{3}$ in chicken eggshells.

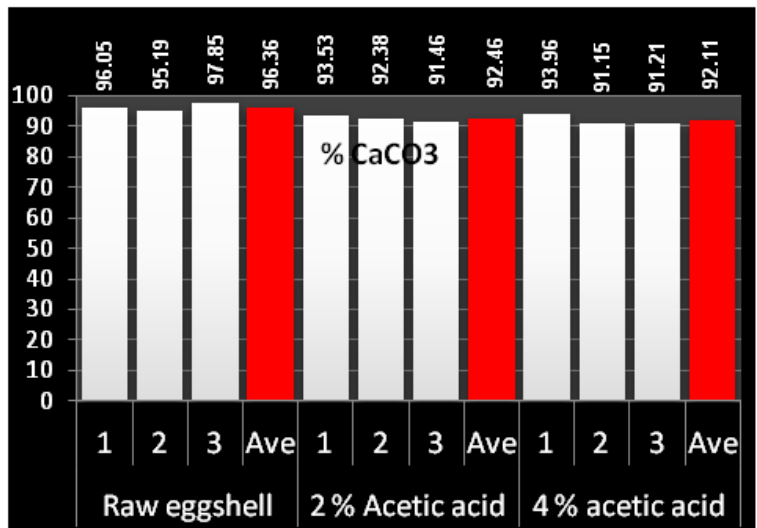

Figure 6. Effect of acetic acid in the Calcium Carbonate content of chicken eggshells.

\section{Preparation of superhydrophobic and oleophilic $\mathrm{CaCO}_{3}$ from chicken eggshells}

Calcium Carbonate obtained from waste chicken eggshells was modified into superhydrophobic and oleophilic Calcium Carbonate to improve the physical and chemical properties of the ChitosanCalcium Carbonate composite film. Calcium Carbonate was treated with stearic acid to improve the oil selectivity. The modified Calcium Carbonate was tested for superhydrophobicity in comparison with the unmodified Calcium Carbonate. Figure 7 illustrates that superhydrophobic Calcium Carbonate formed a suspension, separated from water which indicates an improvement on its physical properties. The impact of Calcium Carbonate on hydrophobicity was primarily attributed to the larger specific surface area of modified Calcium Carbonate. Surface treatment of Calcium Carbonate using stearic acid caused erosion effect on its surface resulting to a rougher and larger surface area.

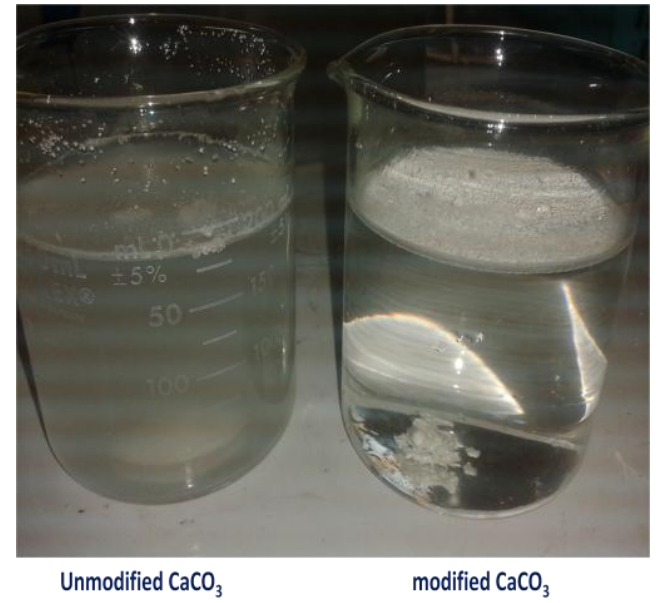

Figure 7. Comparison of modified and unmodified Calcium Carbonate.

\section{Analysis of mechanical properties of Chitosan- $\mathrm{CaCO}_{3}$ composite film}

Figure 8 shows the tensile strength of different composite films (50:50 unmodified, 50:50 modified, 40:60 modified and synthesized Chitosan containing Calcium Carbonate). The 30-70 composite was not included in the analysis because of the weak properties that was observed during preparation. The 50:50 modified composite film exhibits the highest tensile strength of 2.32 MPa while 40:60 modified composite film displays the lowest value of $0.6 \mathrm{MPa}$. The significant increase of tensile strength of 50:50 unmodified to 50:50 modified composite film indicates that superhydrophobic and oleophilic Calcium Carbonate was dispersed homogenously and worked effectively as reinforcement filler in Chitosan composite film. The composite film became more flexible compared with the film made from unmodified Calcium Carbonate. Also, tensile strength of $2.32 \mathrm{MPa}$ proved that the film can sustain higher stress load. 


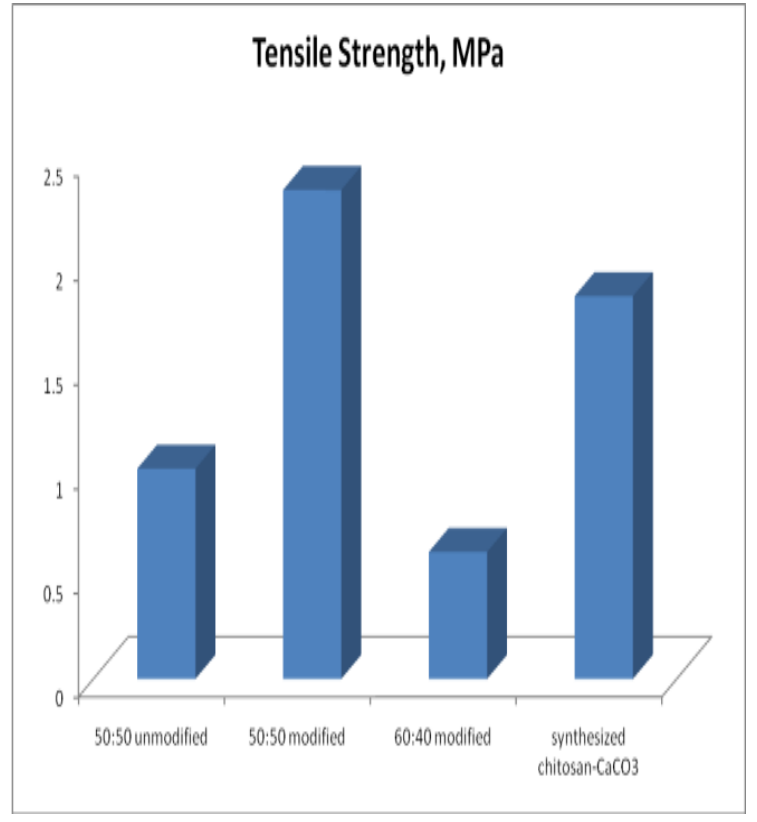

Figure 8. Tensile strength of Chitosan- $\mathrm{CaCO}_{3}$ composite film.

\section{Surface characterization of composite film}

Composite films produced were subjected to surface characterization scanning electron microscopy (SEM) as shown in Figure 9. Different ratios of Chitosan and Calcium Carbonate mixture show rough and coarse microstructures which can be attributed to the presence of modified Calcium Carbonate distributed and embedded in the Chitosan matrix. The Calcium Carbonate crystal surface became rough due to the erosion effect of the stearic acid treatment. The higher proportion of needleshaped Calcium Carbonate crystal in the composite film demonstrated an increase on particles microstructure of Calcium Carbonate. Composite film with 50:50 Calcium Carbonate-Chitosan mixture showed uniform microstructure aggregates of Calcium Carbonate.

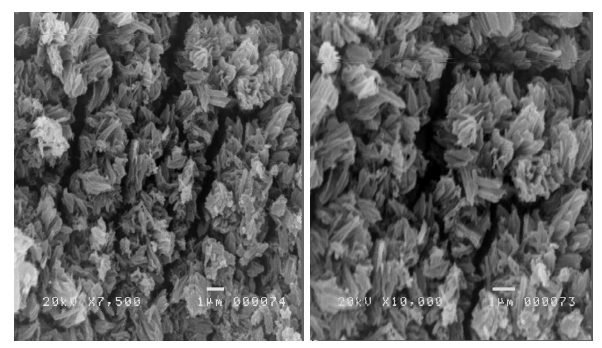

a. 50:50 Chitosan-modified Calcium Carbonate composite film

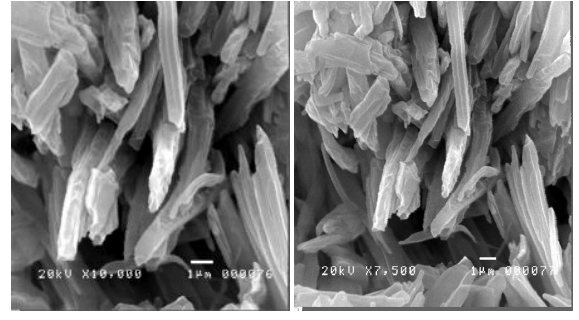

b. 40:60 Chitosan-modified Calcium Carbonate composite film

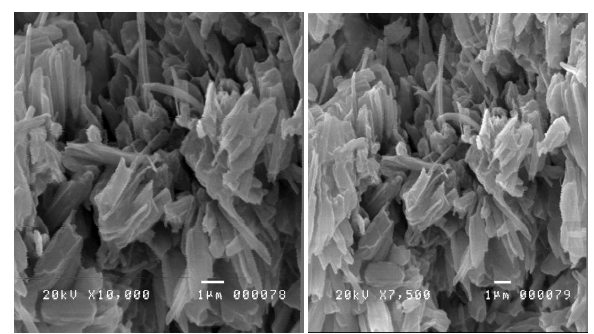

c. 30:70 Chitosan-modified Calcium Carbonate composite film

Figure 9. Scanning electron microscopy photographs of composite films at 7,500x and 10,000x magnifications.

\section{XRD analysis of Chitosan-Calcium Carbonate composite film}

X-ray diffractogram of 50:50 composite film shows sharp peaks at $2 \theta=9.40^{\circ}, 29.7^{\circ}, 37.3^{\circ}$ (Figure 10a). The first sharp peak which is a broad diffraction peak at $2 \theta=9.40^{\circ}$ may be attributed to the crystal form of Chitosan and $2 \theta=29.7^{\circ}$ and $37.3^{\circ}$ featured the calcite polymorph of $\mathrm{CaCO}_{3}$. This was validated by the XRD pattern of pure Calcium Carbonate (Figure 10b) which highlighted the high and sharp peak at $29.8^{\circ}$ and small peaks at $36.1^{\circ}$ and $39.6^{\circ}$. Yen and Mau (2007) found that fungal Chitosan showed crystalline reflection at $9.7^{\circ}$. Prashanth et al. (2002) also found that the WAXD (wide-angle Xray diffraction) patterns of shrimp Chitosan showed major characteristic peak at $2 \theta=9.9-10.7^{\circ}$. Similarly, Zhang and Gonsalves (1998) demonstrated that high peak at $2 \theta=37.6^{\circ}$ and small peaks at $28.8^{\circ}$ represent the (110) and (104) planes of calcite. Also, it was observed from the X-ray diffractogram that lower content of $\mathrm{CaCO}_{3}$, as indicated by less intense peaks, was dispersed in the Chitosan matrix. 
a.

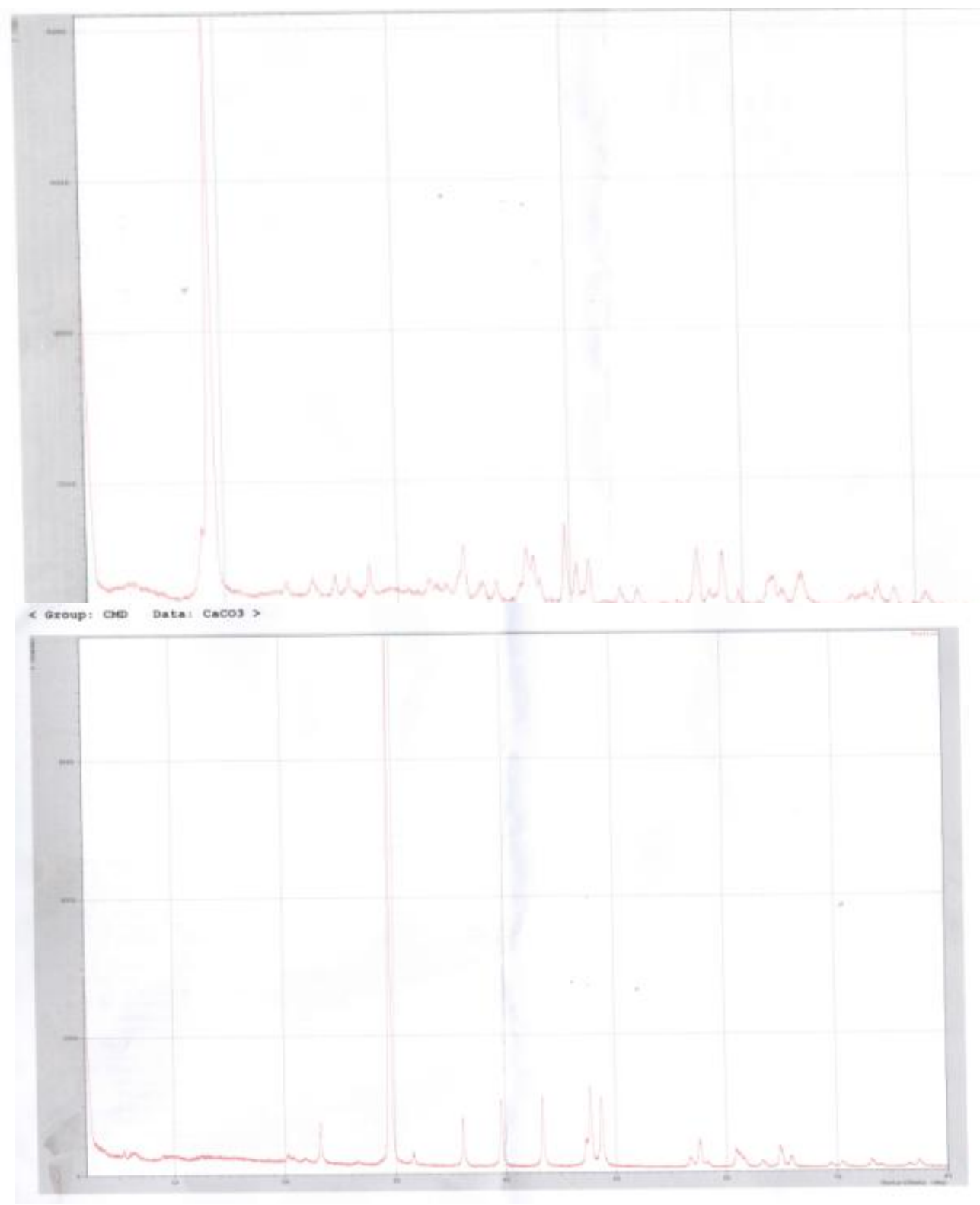

Figure 10. X-ray diffraction patterns of a) Chitosan containing Calcium Carbonate b) Calcium Carbonate

\section{Oil removal efficiency test of Chitosan- Calcium Carbonate composite film}

The oil removal efficiency of Chitosan-Calcium Carbonate composite film is shown in Figure 11. The initial concentration of the simulated vegetable oil contaminated water that was treated is 18,333 $\mathrm{mg} / \mathrm{L}$. A high concentration sample was used to simulate the actual oil spill scenario. Oil removal efficiency test of different Chitosan- $\mathrm{CaCO}_{3}$ composite films demonstrated that 50:50 composite film can remove about $4,670 \mathrm{mg} / \mathrm{L}$ waste vegetable oil while $40: 60$ can treat $4,102 \mathrm{mg} / \mathrm{L}$ and $30: 70$ can adsorb 4,077 mg/L waste oil respectively. Also, Table 1 shows that chitosan- $\mathrm{CaCO}_{3}$ composite film gave the highest diesel oil remove rate of $99.9 \%$. Although, the removal rates of the different composite films have no significant differences, 50:50 composite film was still chosen as optimum ratio due to its physical attributes. 


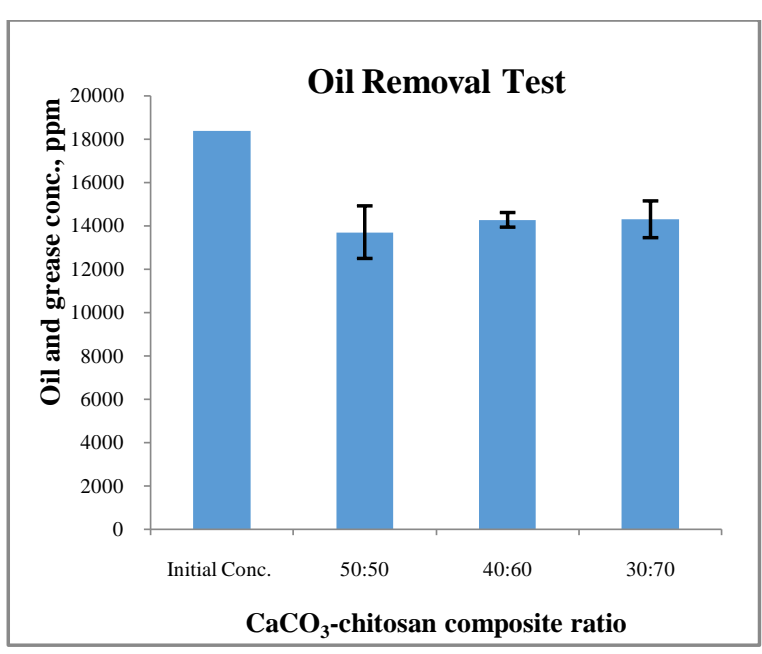

Figure 11. Vegetable oil removal/reduction rate of different Chitosan- $\mathrm{CaCO}_{3}$ composite films.

Table 1. Diesel oil removal efficiency of composite films $(n=3 ;$ rsd $<10 \%)$

\begin{tabular}{|l|l|l|l|}
\hline $\begin{array}{l}\text { Composite } \\
\text { Film } \\
\text { Mixture }\end{array}$ & $\begin{array}{l}\text { Initial } \\
\text { Conc. } \\
(\mathbf{p p m})\end{array}$ & $\begin{array}{l}\text { Final } \\
\text { Conc. } \\
(\mathbf{p p m})\end{array}$ & $\begin{array}{l}\text { \% } \\
\text { Removal } \\
\text { Rate }\end{array}$ \\
\hline $\mathbf{5 0 : 5 0}$ & $\mathbf{5 0 0 0}$ & $\mathbf{5}$ & $\mathbf{9 9 . 9 \%}$ \\
\hline $40: 60$ & $\mathbf{5 0 0 0}$ & 15 & $\mathbf{9 9 . 7 \%}$ \\
\hline $\mathbf{3 0 : 7 0}$ & $\mathbf{5 0 0 0}$ & 15 & $\mathbf{9 9 . 7 \%}$ \\
\hline
\end{tabular}

The oil adsorption mechanism of the composite film may be attributed to the amine functional group of Chitosan which attracts anionic ions to bind and bridge (Osman and Arof, 2003). This factor causes the residue oil to bind and bridge with Chitosan film. Therefore, Chitosan a positively charged biopolymer could adsorb residue oil and destabilize the negatively charged colloids of residue oil and emulsion by charge neutralization mechanism (Jill et al., 1999). Also, the presence of superhydrophobic and oleophilic Calcium Carbonate repels water and attracts oil causing oil to bind on its surface area. The improved surface roughness of $\mathrm{CaCO}_{3}$ increased its oil adsorption capacity. The oil adsorption capacity of 50:50 Chitosan- $\mathrm{CaCO}_{3}$ composite film is $4.03 \mathrm{~g} / \mathrm{g}$ which is 4 times of its weight.

\section{CONCLUSION}

Chitosan- $\mathrm{CaCO}_{3}$ composite obtained from agricultural waste (shrimp shells and chicken eggshells) was successfully developed and applied for the removal of oil (diesel and vegetable) in water. The 50:50 Chitosan- $\mathrm{CaCO}_{3}$ composite exhibited a significantly high oil removal rate both for vegetable and diesel oil. The physical properties of the 50:50 composite film was also considered the best among the other composite ratios. The adsorption of residual oil on Chitosan surface can be explained by charge neutralization mechanism. The adsorption of oil on the cationic biopolymer Chitosan increases the electro-steric repulsion between oil droplets resulting to an enhanced colloidal stability. Also, addition of superhydrophobic $\mathrm{CaCO}_{3}$ on Chitosan matrix promotes repulsion of water and attraction of oil on composite surface area. The improved surface roughness of $\mathrm{CaCO}_{3}$ caused an increase of oil adsorption capacity of the composite materials. The maximum capacity of Chitosan- $\mathrm{CaCO}_{3}$ composite film to adsorb oil (vegetable and diesel) from oilwater mixture was found to be $4.9 \mathrm{~g} / \mathrm{g}$ of adsorbent.

\section{REFERENCES}

Ahmad, M., Usman, A.R.A., Lee, S.S., Kim, S.C., Joo, J.H., Yang, J.E., and Ok, Y.S. (2012) Eggshell and coral wastes as low cost sorbents for the removal of $\mathrm{Pb} 2+$, $\mathrm{Cd} 2+$ and $\mathrm{Cu} 2+$ from aqueous solutions, Journal of Industrial and Engineering Chemistry, Volume 18, Issue 1, 25 January 2012, Pages 198-204

Arbatan,T., Fang, X., and Shen,W., (2011). Superhydrophobic and oleophilic Calcium Carbonate powder as a selective oil sorbent with potential use in oil spills clean-ups. Chemical Engineering Journal Volume 166, Issue 2, 15 January 2011, Pages 787-791

Bernardo, E. C. (2008), Solid-Waste Management Practices of Households in Manila, Philippines. Annals of the New York Academy of Sciences, 1140: 420-424. doi: 10.1196/annals. 1454.016.

Bureau Of Agricultural Statistics (BAS), 2011 Fisheries Situationer January-December 2010. Department of Agriculture, Quezon City, Philippines.

Bureau Of Agricultural Statistics (BAS), 2011 Livestock and Poultry Situationer January-December 2010. Department of Agriculture, Quezon City, Philippines.

Busca, G. and Resini, C. (2000). Vibrational spectroscopy for the analysis of geological and inorganic materials R.A. Meyers (Ed.), Encyclopedia of Analytical Chemistry (UK: John Wiley \& Sons, Chichester). 
Cohen, M. A. (2010), A Taxonomy of Oil Spills Costs. Resources for the Future, Washington D.C., USA.

Dutta, P.K., Dutta, J., And Tripathi, V.S. (2004), Chitin and Chitosan: Chemistry, properties and applications. Journal of Scientific and Industrial, Journal of Scientific and Industrial Research, Volume 23, pages 20-31.

Etkin, D.G. (1999), Estimating Cleanup Costs for Oil Spills. 1999 International Oil Spills Conference \#168.

Ghorbel-Belaaj, O., Younes, I., Maâlej, H., Hajji, S., And Nasri, M. (2012) Chitin extraction from shrimp shell waste using Bacillus bacteria, International Journal of Biological Macromolecules 51. 1196-1201

Jill, R. P., Chihpin, H., Shuchuan, C., and Ying-Chen, C.. "Evaluation of a modified chitosan biopolymer for coagulation of colloidal particles." Colloids Surf. 147, 1999: 359-364.

Lange, J.A.D, 1987, Handbook of Chemistry 13th ed. (New York, USA: McGraw-Hill)

Mendez, J.R.R., Barrios, V.A.E., And Davila-Rodriguez, J.L. (2010). Chitin Based Biocomposites for Removal of Contaminants from Water: a Case Study of Fluoride Adsorption, Biopolymers, Magdy Elnashar (Ed.), InTech, Date of Access: August 2012. http://www.intechopen.com/books/biopolymers/Chitinbased-biocomposites-for-removal-of-contaminants-fromwater-a-case-study-of-fluoride-adsorptio

Osman, Z., Arof, Ak., 2003. FTIR studies of chitosan acetate based polymer electrolytes. Electrochim. Acta. 48 (8),939-999.

Park, H.J., Jeong, S.W., Yang, J.K., Kim, B.G., and Lee, S.M., (2007). Removal of heavy metals using waste eggshell, Journal of Environmetal Sciences, Volume 19, Issue 12, 2007, Pages 1436-1441
Prashanth, K. V. H., Kittur, F. S., Tharanathan, R. N., Solid state structure of chitosan prepared under different $\mathrm{N}$-deacetylating conditions, Carbohydrate Polymers, 2002, 50, p. 27-33.

Stadelman, W.J., (2000). Eggs and egg products. In: Francis, F.J. (Ed.), Encyclopedia of Food Science and Technology, second ed. (New York, USA: John Wiley and Sons) pp. 593-599.

Tolaimate A, Desbrieres J, Rhazi M, Alagui A. (2003). Contribution to the preparation of Chitins and Chitosans with controlled physico-chemical properties. Polymer 2003;44:7939-52.

Tsai, W.T. Yang, J.M. Lai, Y.H. Cheng, C.C. Lin, C.W. (2006), Characterization and adsorption properties of eggshells and eggshell membrane Bioresource Technology, Volume 97, Issue 3, February 2006, Pages 488-493

Witoon, T. (2011). Characterization of Calcium oxide derived from waste eggshell and its application as $\mathrm{CO} 2$ sorbent, Ceramics International, Volume 37, Issue 8, December 2011, Pages 3291-3298

World Bank Philippines Environment Monitor 2006, World Bank, Washington D.C., USA.

Yen, M.-T., Mau, J.-L., Physico-chemical characterization of fungal chitosan from shiitake stipes, LWT-Food Sci. Technol., 2007, 40, p. 472-479.

Zhang Sk; Gonsalves Ke, Influence of the chitosan surface profile on the nucleation and growth of calcium carbonate films, Langmuir, 14(23), 1998, pp. 6761-6766 